Part of Journal of Research of the National Bureau of Standards, Volume 24, February 1940

\title{
PREDICTIONS OF NORMAL RADIO CRITICAL FREQUEN- CIES RELATED TO SOLAR ECLIPSES IN 1940
}

\author{
By Newbern Smith
}

\section{ABSTRACT}

The ordinary-wave critical frequencies of the $E, F_{1}, F_{2}$, and night $F$ layers are predicted for use in ionospheric eclipse observations during the annular solar eclipse of April 7, 1940, and the total solar eclipse of October 1, 1940. The probable reliability and range of application of the data are discussed.

In connection with preparations for ionosphere observations during the solar eclipses of April 7 and October 1, 1940, it is of interest to know the average values of the normal critical frequencies which may be expected in the paths of the eclipse. It is the purpose of this note to give estimates of the expected average values of the ordinarywave critical frequencies of the $E, F_{1}, F_{2}$, and night $F$ layers.

The annular eclipse of April 7 will be observable in northern Mexico and the southern United States. Figure 1 gives the estimated monthly average critical frequencies for a place in Texas $29^{\circ} \mathrm{N}$ and $100^{\circ} \mathrm{W}$ for that month. Figure 2 gives the estimated values for Washington, D. C., for the same month. All predictions are given in terms of monthly averages, and the hours are local times at the given places. The Washington values were obtained by the same procedure as that used in preparing the monthly predictions published in the Proceedings of the Institute of Radio Engineers [1]. ${ }^{1}$ The Texas values were estimated by interpolating between the Washington data and the data for Huancayo, Peru, [2] $12^{\circ} \mathrm{S}$ and $75^{\circ} \mathrm{W}$, for the same season. The graphs for Texas may be used for other locations in the United States in the path of the eclipse.

The total eclipse of October 1 will be observable in northern South America and in South Africa. Figure 3 gives estimated monthly average critical frequencies for Huancayo, Peru, $12^{\circ} \mathrm{S}$ and $75^{\circ} \mathrm{W}$, for this month. These values may be considered as representative of the values to be encountered in northern South America. Figure 4 gives estimated monthly average critical frequencies for Watheroo, Western Australia, $30^{\circ} \mathrm{S}$ and $116^{\circ} \mathrm{E}$, for October. It is believed that these values may be used for the South African location at approximately the same geographic latitude, although, owing to the differences in longitude and magnetic latitude, they may not be as reliable. The data of figures 3 and 4 were obtained by the same procedure as for Washington, using the available published data for Huancayo [2] and Watheroo [3].

\footnotetext{
1 Figures in brackets indicate the literature references at the end of this paper.
} 


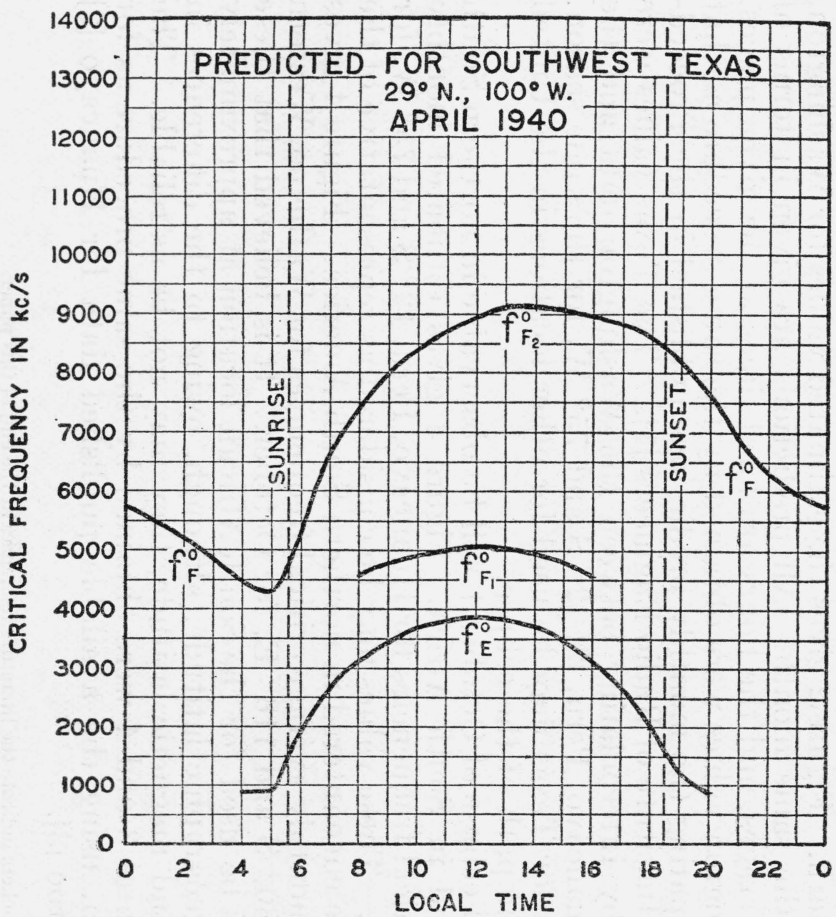

FiguRe 1.-Predicted average critical frequencies of the $E, F_{1}, F_{2}$ and night $F$ layers for undisturbed days in April 1940, for a place in Texas $100^{\circ} \mathrm{W}$ and $29^{\circ} \mathrm{N}$.

Abscissas are local times. These graphs may be used in northern Mexico or at other places in the southern United States whose latitudes are not much different from
$29^{\circ} \mathrm{N}$.

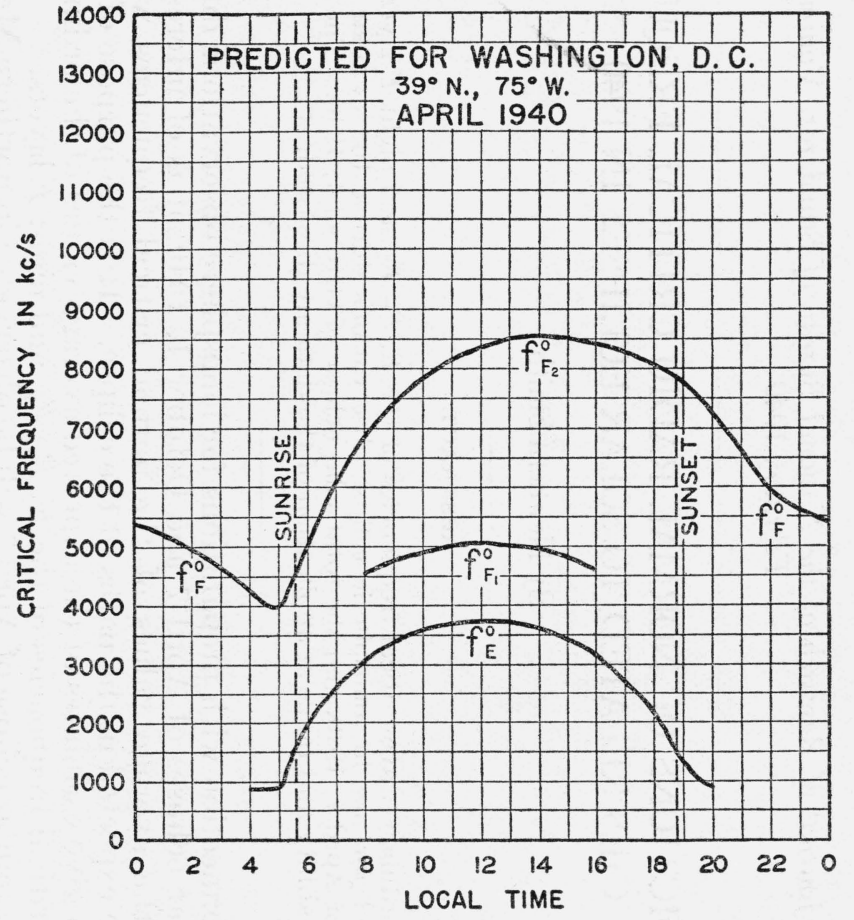

FIGURE 2.-Predicted average critical frequencies of the $E, F_{1}, F_{2}$, and night $F$ layers for undisturbed days in April 1940, for Washington, D. C. 


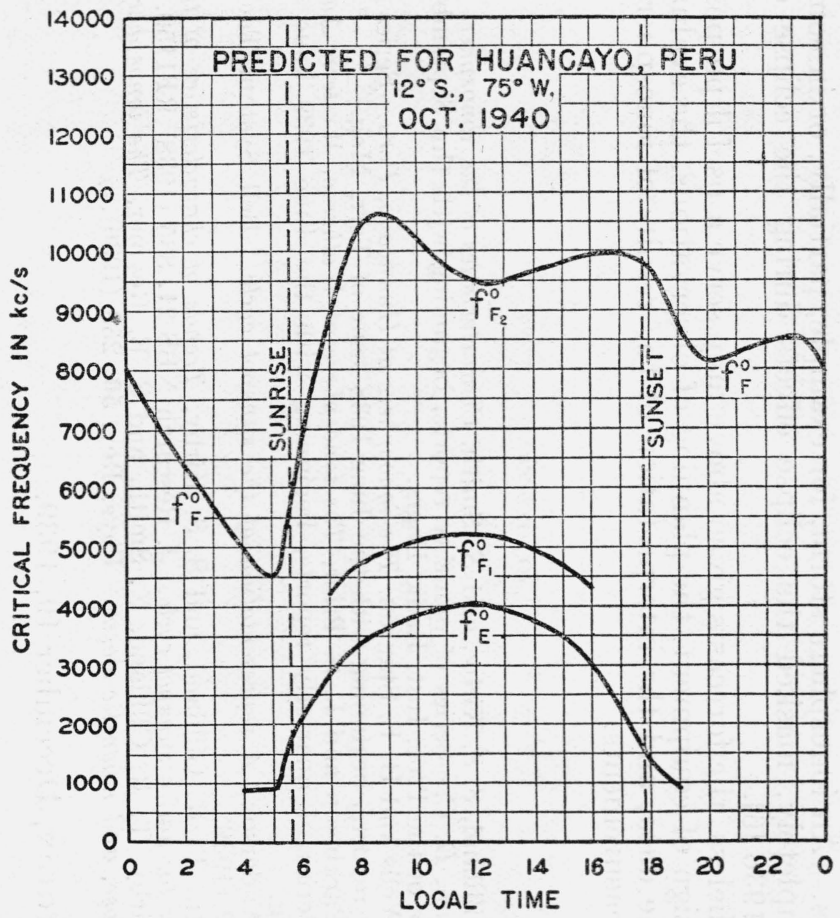

FiguRe 3.- Predicted average critical frequencies of the $E, F_{1}, F_{2}$, and night $F$ layers for undisturbed days in October 1940, for Huancayo, Peru, $75^{\circ} \mathrm{W}$ and $12^{\circ} \mathrm{S}$.

Abscissas are local times. These graphs may he used for places in northern South America whose latitndes do not differ greatly from $12^{\circ} \mathrm{S}$

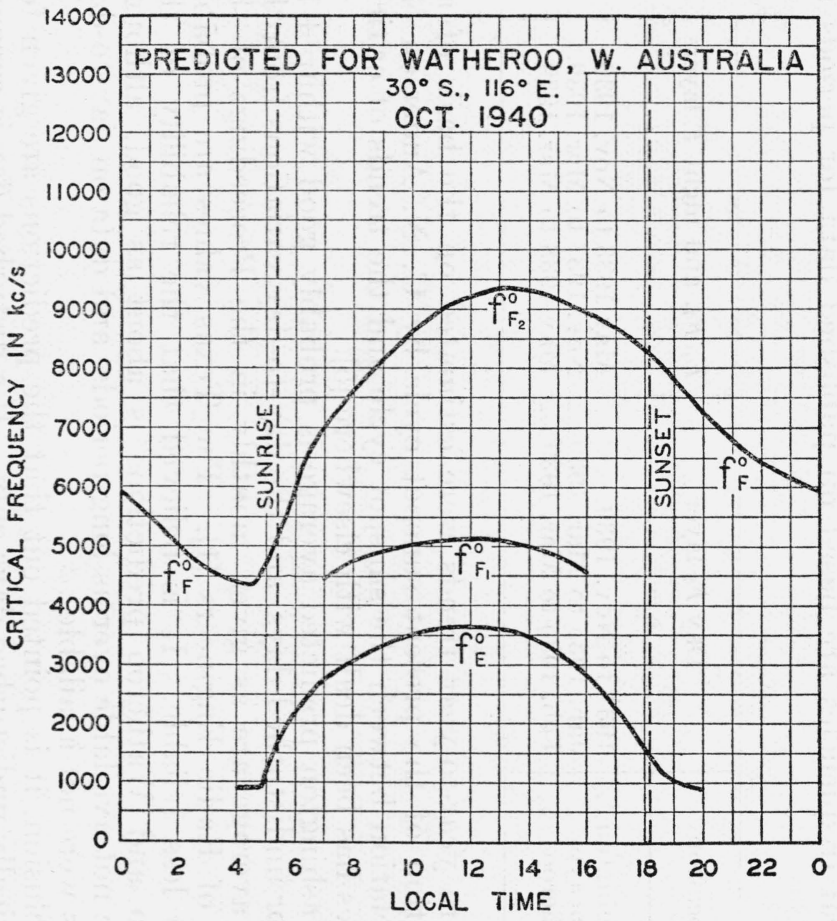

FIGURE 4.-Predicted average critical frequencies of the $E, F_{1}, F_{2}$, and night $F$ layers for undisturbed days in October 1940, for Watheroo, Western Australia, $116^{\circ} \mathrm{E}$ and $30^{\circ} \mathrm{S}$.

Abscissas are local times. These grapbs may be used for places in South Africa whose latitudes do not differ greatly from $30^{\circ} \mathrm{S}$. 
The diurnal and seasonal variations and the year-to-year trends of the critical frequencies are based on published data for periods as follows:

\begin{tabular}{|c|c|c|}
\hline Location & \multicolumn{1}{|c|}{ Day $F_{2}$ layer } & $E, F_{1}$, and night $F$ layers \\
\hline Washington_-- & $\begin{array}{l}\text { 1931 to Nov. 1939_-19 } \\
\text { Jan. 1935 to Mar. 1939_-- }\end{array}$ & $\begin{array}{l}\text { May 1933 to Nov. 1939. } \\
\text { Nov. 1937 to Mar. 1939. }\end{array}$ \\
$\begin{array}{l}\text { Huancayo_-_- } \\
\text { Watheroo_-- }\end{array}$ & Feb. 1935 to Mar. 1939_-- & May 1938 to Mar. 1939. \\
\hline
\end{tabular}

The future year-to-year trends were estimated on the basis of an extrapolation of the present sunspot cycle by C. N. Anderson [4]. The correlation between the sunspot cycle and the trends of critical frequencies has been dealt with elsewhere [5].

The Washington predicted average is probably good within \pm 15 percent for undisturbed days, and the day-to-day variations from the monthly average are as given monthly in the Proceedings of the Institute of Radio Engineers [1]. The Texas values are probably but little less reliable. It is believed that the reliability of the Huancayo and Watheroo predictions is about as good, although data were not available over as long periods, and data on day-to-day variations were not available.

In conclusion, it is pointed out that the predictions are given for ionospherically undisturbed days only. If a disturbed day is encountered, the values observed may differ widely from the estimates, the difference being greater the nearer the observer is to one of the magnetic poles. An ionosphere storm, for example, partially, or in some cases completely, masked the eclipse effects during the eclipse of June 19, 1936 [6].

Nevertheless, the forecasts given above may serve a useful purpose in the design of equipment, the planning of observations, the evaluation of the data, and the interpretation of the results of ionospheric eclipse measurements.

\section{References}

[1] T. R. Gilliland, S. S. Kirby, and N. Smith, Characteristics of the ionosphere at Washington, D. C. Series of monthly reports, beginning with the September 1937 issue of the Proc. Inst. Radio Engrs.

[2] H. W. Wells and H. E. Stanton, The ionosphere at Huancayo, Peru. Series of quarterly reports, beginning with the June 1938 issue of Terr. Mag.

[3] W. C. Parkinson and L. S. Prior, The ionosphere at Watheroo, Western Australia. Series of quarterly reports, beginning with the June 1939 issue of Terr. Mag.

[4] C. N. Anderson, A representation of the sunspot cycle. Bell System Tech. J. 18, 292 (1939).

[5] N. Smith, T. R. Gilliland, and S. S. Kirby, Trends of characteristics of the ionosphere for half a sunspot cycle. J. Research NBS 21, 835 (1938) RP1159.

[6] S. S. Kirby, T. R. Gilliland, N. Smith, and S. E. Reymer, The ionosphere, solar eclipse, and magnetic storm. Phys. Rev. 50, 258 (1936).

Washington, December 19, 1939. 